\title{
Histomorphometric and Histopathologic Evaluation of the Effects of Systemic Fluoride Intake on Orthodontic Tooth Movement
}

\author{
Fatma Yalcin Zorlu ${ }^{1}$ Hakan Darici ${ }^{2, \oplus}$ Hakan Turkkahraman ${ }^{1,3, \oplus}$ \\ ${ }^{1}$ Department of Orthodontics, School of Dentistry, University of \\ Suleyman Demirel, Isparta, Turkey \\ 2Department of Histology \& Embryology, School of Medicine, \\ University of Suleyman Demirel, Isparta, Turkey \\ ${ }^{3}$ Department of Orthodontics and Oral Facial Genetics, School of \\ Dentistry, Indiana University, Indianapolis, Indiana, United States
}

Address for correspondence Hakan Turkkahraman, DDS, PhD, IU School of Dentistry, 1121 W Michigan St. DS249, Indianapolis, IN, 46202, United States (e-mail: haturk@iu.edu).

Eur J Dent 2019;13:361-369

\begin{abstract}
Objectives The aim of this study was to determine the effects of systemic fluoride intake on orthodontic tooth movement with histomorphometric and histopathologic methods. Materials and Methods Forty-eight Wistar albino rats were randomly divided into four groups of 12 rats each. Group I received fluoridated water and underwent orthodontic tooth movement. Group II received fluoridated water and did not undergo orthodontic tooth movement. Group III received nonfluoridated water and underwent orthodontic tooth movement. Group IV received nonfluoridated water and did not undergo orthodontic tooth movement. At the beginning of the experiment (T1), impressions were taken from the maxilla of the rats in groups I and III under general anesthesia, and a NiTi closed coil spring appliance was ligated between the left maxillary central incisors and maxillary first molar. The orthodontic force applied was approximately $75 \mathrm{~g}$, and the duration of the experimental period was 18 days. During the experimental period, appliances were controlled daily. At the end of the experimental period (T2), the rats were sacrificed with an overdose of a ketamine/xylasine combination, and their impressions were obtained. The upper first molars were subsequently dissected for histological examination. Incisormolar distance, number of osteoblasts, number of osteoclasts and periodontal ligament (PDL) space widths on the compression and tension sides were measured.

Statistical Analysis All measurements were statistically analyzed with SPSS for Windows version 18.0 (SPSS Inc., Chicago, IL, USA). Repeated measures ANOVA and posthoc Tukey tests were used to compare the groups.

Results No statistically significant difference was found with respect to the amount of tooth movement between the fluoridated and nonfluoridated groups $(p>0.05)$. Ortho-

Keywords

- fluorosis

- orthodontic tooth movement

- root resorption

- histomorphometry dontic force application increased the number of osteoblasts at the tension sides and reduced it at the compression sides $(p<0.001)$. An increased number of osteoclasts was observed in the nonfluoridated group relative to the fluoridated group $(p<0.01)$. Conclusions No difference was observed with respect to the amount of tooth movement between the fluoridated and nonfluoridated groups. Fluoride significantly reduced the number of osteoclasts in the experimental groups.
\end{abstract}




\section{Introduction}

With the growing importance given to aesthetics, orthodontic treatments today have become more popular. Orthodontic tooth movement involves bone remodeling and requires a close interplay between bone formation by osteoblasts and bone resorption by osteoclasts. During tooth movement, mechanical stresses in the periodontal ligament (PDL) space induce cellular reactions. Clinical experience has demonstrated that there is significant individual variation in the velocity of orthodontic tooth movement, and one can assume that the velocity is influenced by factors such as nutritional state, hormones, vitamins, and trace elements. ${ }^{1,2}$

Fluoride is an important micronutrient that accumulates within mineralized tissues such as teeth and bone. Fluoride has been demonstrated, both experimentally and clinically, to stimulate bone formation directly, and increase bone mass in patients who exhibit osteoporosis. ${ }^{3,4}$ Fluoride influences bone growth by acting as a mitogenic agent for osteoblasts ${ }^{5,6}$ and might also directly inhibit the activity of osteoclasts by preventing calcium ion release and directly suppressing osteoclast acidity. ${ }^{7}$ Furthermore, fluoride decreases the numbers of resorption lacunae as well as the amount of bone resorbed by osteoclasts. ${ }^{8}$

Endemic fluorosis is defined as chronic fluorine intoxication affecting the teeth, theskeleton, and the nervous system. Endemic fluorosis is generally observed in certain parts of the world where there is excessive fluorine in the water and soil. ${ }^{9}$ Dental fluorosis is defined as the developmental anomaly of the enamel caused by excessive exposure to high concentrations of fluoride during tooth development. In the clinical setting, severe dental fluorosis can delay orthodontic tooth movement because of changes in bone metabolism.

In the literature, there is some evidence that the osteogenic characteristics of fluoride affect orthodontic tooth movement by increasing osteoblastic activity. ${ }^{1,2}$ However, only a few studies have evaluated the effects of systemic fluoride intake on orthodontic tooth movement. ${ }^{1,10-13}$ In three of these studies, fluoride was administered only during the experimental tooth movement. ${ }^{1,10,11}$ In a recent study by Gonzales et al, ${ }^{12}$ sodium fluoride (NaF) was administered to Wistar rats from birth to 2,4 , and 12 weeks. The authors found that the duration of fluoride intake was negatively correlated with the amount of tooth movement. Karadeniz et $\mathrm{al}^{13}$ evaluated the effects of heavy/light forces and high/low fluoride concentrations in drinking water at the early stages of tooth movement in humans. To our knowledge, there exists no experimental study evaluating the effects of systemic fluoride intake from gestation, birth to adulthood on orthodontic tooth movement. Therefore, the primary aim of this study was to determine the effects of systemic fluoride intake on orthodontic tooth movement with histomorphometric and histopathologic methods. The second specific aim of this study was to find the effects of fluoride on osteoblastic and osteoclastic activity. The third aim of this study was to determine the effect of fluoride on root resorbtion of orthodontically moved teeth. Our null hypothesis was as follows: "There is no effect of systemic fluoride intake on orthodontic tooth movement."

\section{Materials and Methods}

This study was approved by the University of Suleyman Demirel Regional Animal Research Ethical Committee. At the beginning of the experiment, 16 twelve-week-old Wistar albino pregnant rats were used. The rats were randomly divided into two equal groups. The rats in the first group received 150 ppm fluoridated water, whereas the second group received bottled water during the gestation period. After birth, 48 male pups were randomly divided into four groups of 12 rats each when they were 12 to 13 weeks old. Group I received fluoridated water and underwent orthodontic tooth movement. Group II received fluoridated water and did not undergo orthodontic tooth movement. Group III received nonfluoridated water and underwent orthodontic tooth movement. Group IV received nonfluoridated water and did not undergo orthodontic tooth movement (-Table 1).

At the beginning of the experiment (T1), impressions were taken from the maxilla of the rats in groups I and III under general anesthesia, and a NiTi closed coil spring appliance was ligated between the left maxillary central incisors and maxillary first molar. A retractor was used to hold back the soft tissues and hold the head securely (-Fig. 1). ${ }^{14}$ The orthodontic force applied was approximately $75 \mathrm{~g}$, and the duration of the experimental period was 18 days. During the experimental period, appliances were controlled daily. At the end of the experimental period (T2), the rats were sacrificed with an overdose of a ketamine/xylasine combination, and their impressions were obtained. The upper first molars were subsequently dissected for histological examination.

The dissected molars were fixed in $10 \%$ neutral formaldehyde and decalcified in 10\% EDTA for 6 to 7 weeks, dehydrated, embedded in paraffin, and sectioned in a buccolingual direction as parallel as possible to the long axis of the roots

Table 1 Description of the groups

\begin{tabular}{|l|l|}
\hline Group I $(n=12)$ & Fluoridated water + force \\
\hline Group II $(n=12)$ & Fluoridated water + no force \\
\hline Group III $(n=12)$ & Nonfluoridated water + force \\
\hline Group IV $(n=12)$ & Nonfluoridated water + no force \\
\hline
\end{tabular}

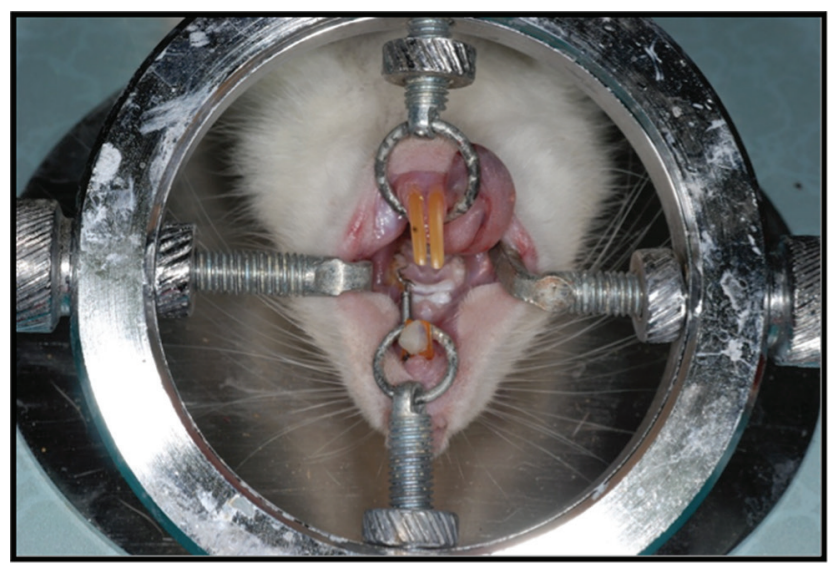

Fig. 1 The ecarteur and the orthodontic appliance in situ. 
of the upper first molars with a section thickness of $4 \mu \mathrm{m}$. Sections from the central region of the mesial root were used in the study. Serial sections from each animal were stained with hematoxylin-eosin.

All parameters were quantified on these sections using Clemex Vision Lite 3.5 Image Analysis Software (Clemex Technologies Inc., Quebec, Canada) coupled to light microscopy. The areas for measurement in the groups included the mesial and distal aspects of the mesial root. The measurements performed were as follows: numbers of osteoblasts, numbers of osteoclasts, and PDL space widths on the compression and tension sides.

Dental cast models were used to assess the amount of tooth movement. For these measurements, a split-mouth design was used, with the left side as the experimental side and the right side as the control. The distance between the most mesial point of the maxillary molar and the enamelcementum border of the ipsilateral maxillary incisor at the gingival level was measured at the experimental and control sides on dental models.

\section{Statistical Analysis}

All measurements were statistically analyzed with SPSS for Windows version 18.0 (SPSS Inc., Chicago, IL, USA). Repeated measures ANOVA and posthoc Tukey tests were used to compare the groups.

\section{Results}

Descriptive statistics of all variables are presented in - Table 2. With repeated measures ANOVA, interactions between water (fluoridated and nonfluoridated), time (T1 and $\mathrm{T} 2$ ), force (orthodontic force and no orthodontic force), and side (compression and tension) factors were investigated.

\section{Orthodontic Tooth Movement Evaluation}

The results of ANOVA revealed a statistically significant interaction between the time and force factors $(p<0.001)$. The results of the posthoc Tukey test are presented in $\boldsymbol{-}$ Tables $\mathbf{3}$ and $\mathbf{4}$.

At the beginning of the experiment (T1), no significant difference was observed between the incisor-molar distance of the rats in the experimental and control groups $(p>0.05)$. After force application, the incisor-molar distance in the experimental groups significantly decreased $(p<0.001)$. In the experimental groups, the mean orthodontic tooth movement was $0.70 \mathrm{~mm}$. No statistically significant difference was observed in the amount of tooth movement between the fluoridated $(0.65 \mathrm{~mm})$ and nonfluoridated $(0.76 \mathrm{~mm})$ groups $(p>0.05)$.

Table 2 Descriptive statistics of the variables

\begin{tabular}{|l|l|l|l|l|l|l|l|l|}
\hline \multirow{2}{*}{} & \multicolumn{2}{|c|}{ Group I } & \multicolumn{2}{c|}{ Group II } & \multicolumn{2}{c|}{ Group III } & \multicolumn{2}{c|}{ Group IV } \\
\cline { 2 - 10 } & Mean & SD & Mean & SD & Mean & SD & Mean & SD \\
\hline Incisor-molar distance (T1) & 12.41 & 0.42 & 12.39 & 0.43 & 12.01 & 0.30 & 11.97 & 0.37 \\
\hline Incisor-molar distance (T2) & 11.76 & 0.46 & 12.27 & 0.41 & 11.25 & 0.38 & 11.85 & 0.35 \\
\hline Osteoblast compression side & 2.70 & 0.24 & 3.73 & 0.51 & 3.21 & 0.37 & 3.74 & 0.56 \\
\hline Osteoblast tension side & 3.68 & 0.17 & 3.75 & 0.64 & 3.74 & 0.48 & 3.63 & 0.80 \\
\hline Osteoclast compression side & 1.66 & 0.13 & 0.90 & 0.35 & 2.54 & 0.87 & 0.99 & 0.35 \\
\hline Osteoclast tension side & 0.73 & 0.15 & 0.85 & 0.25 & 1.11 & 0.36 & 1.02 & 0.33 \\
\hline PDL space width compression side & 68.92 & 35.51 & 65.14 & 12.96 & 42.83 & 33.24 & 101.45 & 17.71 \\
\hline PDL space width tension side & 101.69 & 32.53 & 70.97 & 8.67 & 94.06 & 61.12 & 75.99 & 22.18 \\
\hline
\end{tabular}

Table 3 Incisor-molar distances of the fluoridated and nonfluoridated groups

\begin{tabular}{|l|l|l|l|l|l|l|}
\hline \multirow{2}{*}{ Groups } & \multicolumn{3}{|c|}{ T1 } & \multicolumn{2}{c|}{ T2 } & \multicolumn{2}{c|}{ Total } \\
\cline { 2 - 7 } & Mean & SD & Mean & SD & Mean & SD \\
\hline Fluoridated & 12.39 & 0.10 & 12.01 & 0.11 & 12.21 & $0.10 \mathrm{~A}$ \\
\hline Nonfluoridated & 11.99 & 0.10 & 11.55 & 0.11 & 11.77 & $0.10 \mathrm{~B}$ \\
\hline
\end{tabular}

Note: Capital letters reveal significant differences between the fluoridated and nonfluoridated groups.

Table 4 Incisor-molar distances of the experimental and control groups

\begin{tabular}{|l|l|l|l|l|}
\hline \multirow{2}{*}{ Groups } & \multicolumn{2}{|c|}{ T1 } & \multicolumn{2}{c|}{ T2 } \\
\cline { 2 - 5 } & Mean & SD & Mean & SD \\
\hline Experimental & 12.21 & 0.07 a & 11.51 & 0.08 bb \\
\hline Control & 12.18 & 0.08 a & 12.06 & 0.07 ba \\
\hline
\end{tabular}

Note: Small letters reveal significant differences between T1 and T2, and small bold and italic letters reveal significant differences between the experimental and control groups. 


\section{Histomorphometric Evaluation}

The results of ANOVA revealed a statistically significant interaction between force and side factors with respect to the number of osteoblasts $(p<0.001)$. The results of the posthoc Tukey test are presented in $\mathbf{- T a b l e} \mathbf{5}$.

The number of osteoblasts at the tension sides of the teeth were significantly higher in both experimental groups (Groups I and III) than in the control groups (Groups II and IV) $(p<0.001)$. However, the number of osteoblasts at the compression sides of the teeth in control groups (Groups II and IV) was higher than in the experimental groups. No significant effect of fluoride on the number of osteoblasts was observed $(p>0.05)$. Orthodontic force application increased the number of the osteoblasts at the tension sides and reduced the number at the compression sides.

With respect to the number of osteoclasts, the results of ANOVA revealed statistically significant interactions between water and force factors $(\mathrm{p}<0.01)$ and between force and side factors $(p<0.001)$. The results of the posthoc Tukey test are presented in - Tables 6 and $\mathbf{7}$.

The number of osteoclasts was significantly higher in both experimental groups (Groups I and III) than in the control groups (Groups II and IV) $(p<0.01)$. Orthodontic force application significantly increased the number of osteoclasts. When the experimental groups compared with each other, an increased number of osteoclasts was observed in the nonfluoridated group (Group III) relative to the fluoridated group (Group I) $(p<0.01)$. Systemic fluoride intake reduced the number of osteoclasts near the orthodontically moved teeth. In experimental groups, osteoclastic activity at the compression side of the roots was higher than it was at the tension side $(p<0.001)$. More resorption and more osteoclastic activity were observed in the force direction.

In the PDL space widths, the results of ANOVA revealed a statistically significant interaction between side, water, and force factors $(p<0.05)$. The results of the posthoc Tukey test are presented in - Table 8 .

Table 5 Number of the osteoblasts at compression and tension sides of a molar tooth in the experimental and control groups

\begin{tabular}{|l|l|l|l|l|}
\hline \multirow{2}{*}{ Groups } & \multicolumn{2}{|c|}{ Experimental } & \multicolumn{2}{c|}{ Control } \\
\cline { 2 - 5 } & Mean & SD & Mean & SD \\
\hline Compression side & 8.53 & $0.86 \mathrm{Bb}$ & 13.94 & $0.86 \mathrm{Bb}$ \\
\hline Tension side & 13.58 & $0.99 \mathrm{Aa}$ & 14.25 & $0.99 \mathrm{Aa}$ \\
\hline
\end{tabular}

Note: Capital letters reveal significant differences between compression and tension sides, and small letters reveal significant differences between the experimental and control groups.

Table 6 Number of the osteoclasts in the fluoridated and nonfluoridated experimental and control groups

\begin{tabular}{|l|l|l|l|l|}
\hline \multirow{2}{*}{ Groups } & \multicolumn{2}{|c|}{ Experimental } & \multicolumn{2}{c|}{ Control } \\
\cline { 2 - 5 } & Mean & SD & Mean & SD \\
\hline Fluoridated & 1.32 & $0.20 \mathrm{Ab}$ & 0.47 & $0.20 \mathrm{Ba}$ \\
\hline Nonfluoridated & 2.87 & $0.19 \mathrm{Aa}$ & 0.83 & $0.19 \mathrm{Ba}$ \\
\hline
\end{tabular}

Note: Capital letters reveal significant differences between the experimental and control groups, and small letters reveal significant differences between the fluoridated and nonfluoridated groups.

Table 7 Number of the osteoclasts at compression and tension sides of a molar tooth in the experimental and control groups

\begin{tabular}{|l|l|l|l|l|}
\hline \multirow{2}{*}{ Groups } & \multicolumn{2}{|c|}{ Experimental } & \multicolumn{2}{c|}{ Control } \\
\cline { 2 - 5 } & Mean & SD & Mean & SD \\
\hline Compression side & 3.58 & $0.20 \mathrm{Aa}$ & 0.68 & $0.20 \mathrm{Ab}$ \\
\hline Tension side & 0.60 & $0.15 \mathrm{Aa}$ & 0.62 & $0.15 \mathrm{Aa}$ \\
\hline
\end{tabular}

Note: Capital letters reveal significant differences between the compression and tension sides, and small letters reveal significant differences between the experimental and control groups.

Table 8 The PDL space widths $(\mu \mathrm{m})$ in the experimental and control groups

\begin{tabular}{|l|l|l|l|l|l|}
\hline \multirow{2}{*}{} & \multirow{2}{*}{} & \multicolumn{3}{|c|}{ Fluoridated } & \multicolumn{2}{c|}{ Nonfluoridated } \\
\cline { 3 - 6 } & & Mean & SD & Mean & SD \\
\hline \multirow{3}{*}{ Experimental } & Compression side & 68.92 & $10.12 \mathrm{Ba} \boldsymbol{a}$ & 42.83 & $10.12 \mathrm{Bb} \boldsymbol{b}$ \\
\cline { 2 - 6 } & Tension side & 101.69 & $13.92 \mathrm{Aa} \boldsymbol{a}$ & 94.06 & $13.92 \mathrm{Aa} \boldsymbol{a}$ \\
\hline \multirow{2}{*}{ Control } & Compression side & 65.14 & $10.93 \mathrm{Aa} \boldsymbol{b}$ & 101.45 & $9.47 \mathrm{Aa} \boldsymbol{a}$ \\
\cline { 2 - 6 } & Tension side & 70.97 & $15.04 \mathrm{Ab} \boldsymbol{a}$ & 75.99 & $13.02 \mathrm{Bb} \boldsymbol{a}$ \\
\hline
\end{tabular}

Note: Capital letters reveal significant differences between the compression and tension sides, small letters reveal significant differences between the experimental and control groups, and small bold italic letters reveal significant differences between the fluoridated and nonfluoridated groups. 
After orthodontic force application, both experimental groups (Groups I and III) exhibited wider PDL space widths at the tension side than the compression side $(p<0.05)$. In experimental groups, PDL space widths at the compression side were wider in the fluoridated group (Group I) than in the nonfluoridated group (Group III) $(p<0.05)$. No significant difference was observed between the tension side PDL space widths of the fluoridated and nonfluoridated experimental groups (Groups I and III).

\section{Histopathological Evaluation}

In the control groups, PDL and alveolar bone around the upper 1st molar teeth were histologically normal ( - Fig. 2). The PDL structure was composed of tight cellular connective tissue, collagen fibers, and a few blood vessels adjacent to the alve-

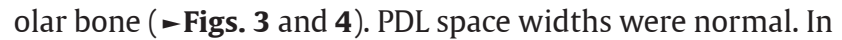
the alveolar bone surface adjacent to PDL, many osteoblasts and few multinucleated osteoclasts were observed ( - Fig. $\mathbf{3}$ ). Root surfaces exhibited straight and smooth boundaries. No significant difference was observed between the fluoridated and nonfluoridated groups ( - Figs. 3 and $\mathbf{4}$ ).

In the experimental groups, resorptive alveolar bone surfaces were observed at the compression side, and depository alveolar bone surfaces were observed at the tension side. At the compression side, the PDL space was narrowed, and compression of the periodontal fibers was observed. At the

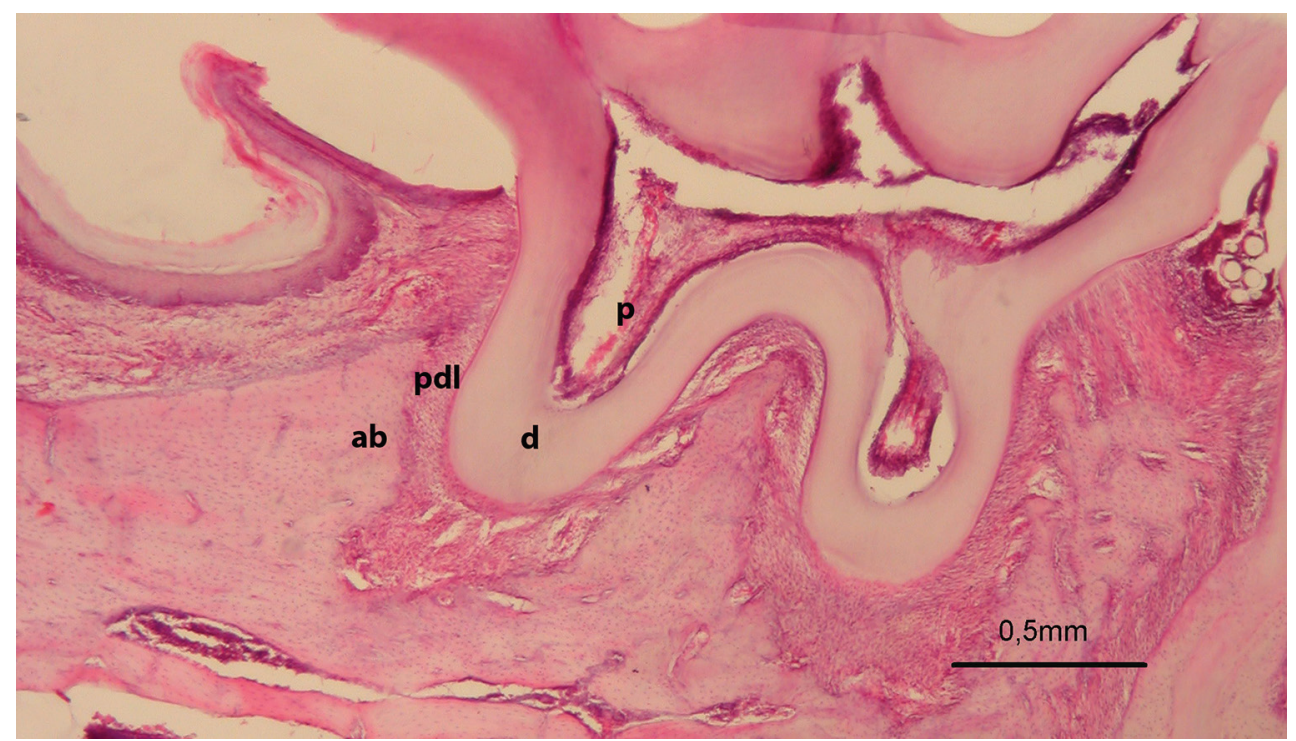

Fig. 2 A histologic section of a molar tooth from the nonfluoridated control group. ab: alveolar bone, p: pulp, d: dentine, pdl: periodontal ligament.

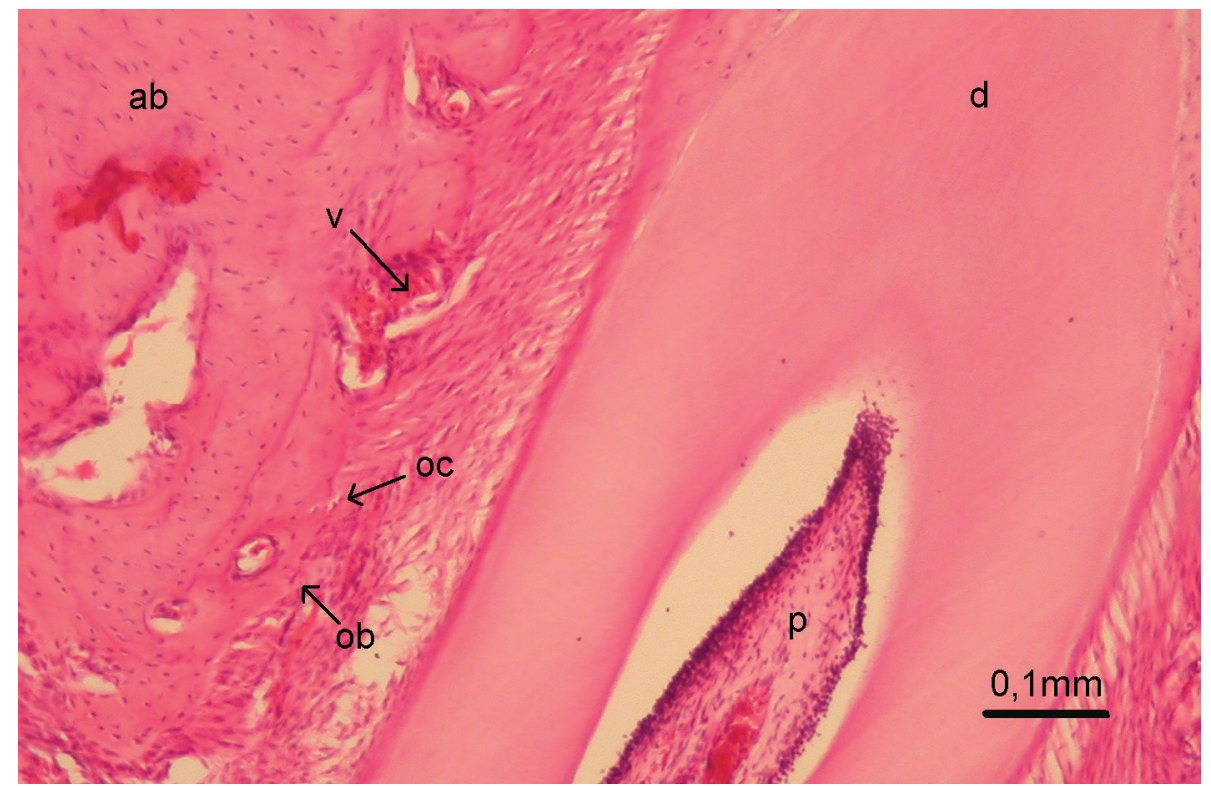

Fig. 3 A histologic section of a molar root from the fluoridated control group. ab: alveolar bone, p: pulp, d: dentine, ob: osteoblast, oc: osteoclast. 


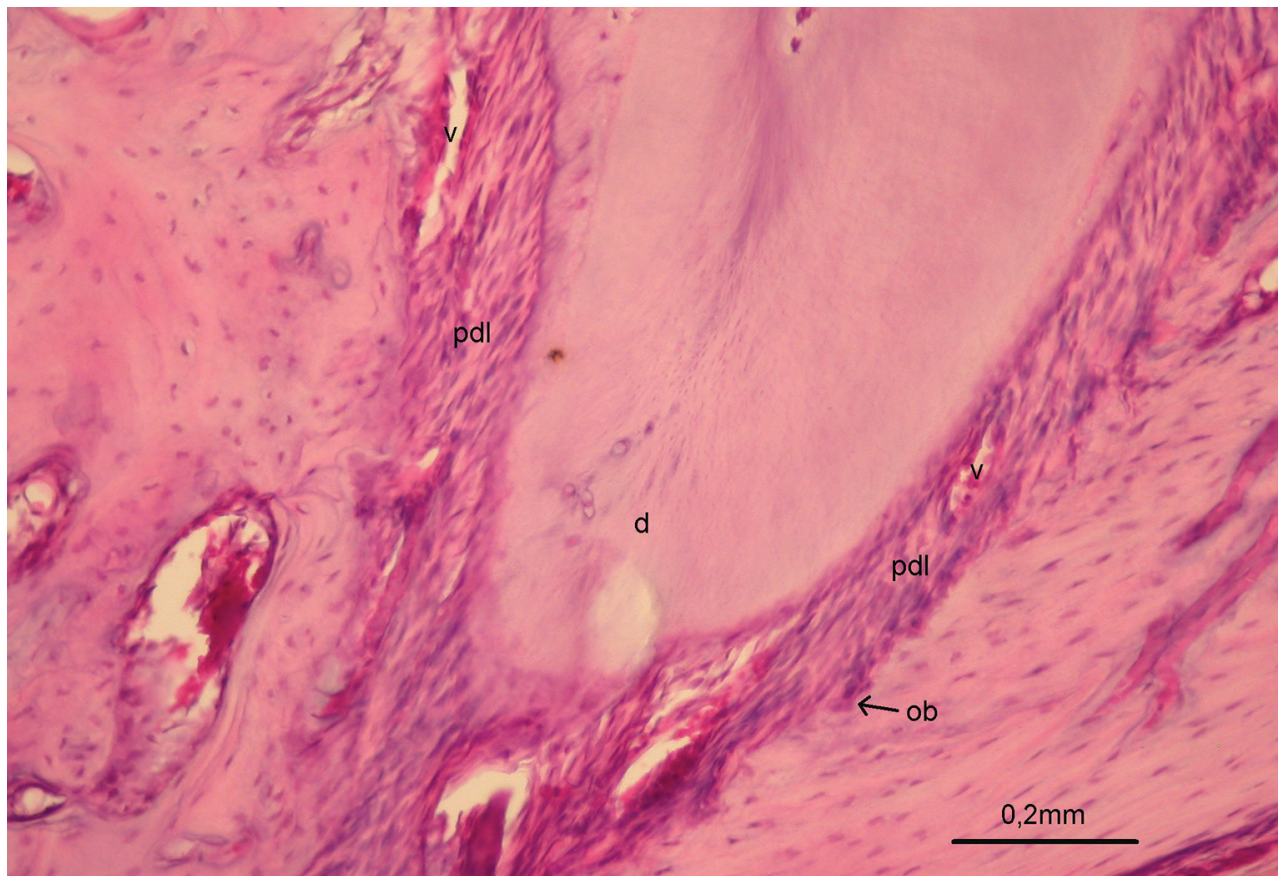

Fig. 4 A histologic section of a molar root from the fluoridated control group. pdl: periodontal ligament, d: dentine, ob: osteoblast, v: blood vessel.

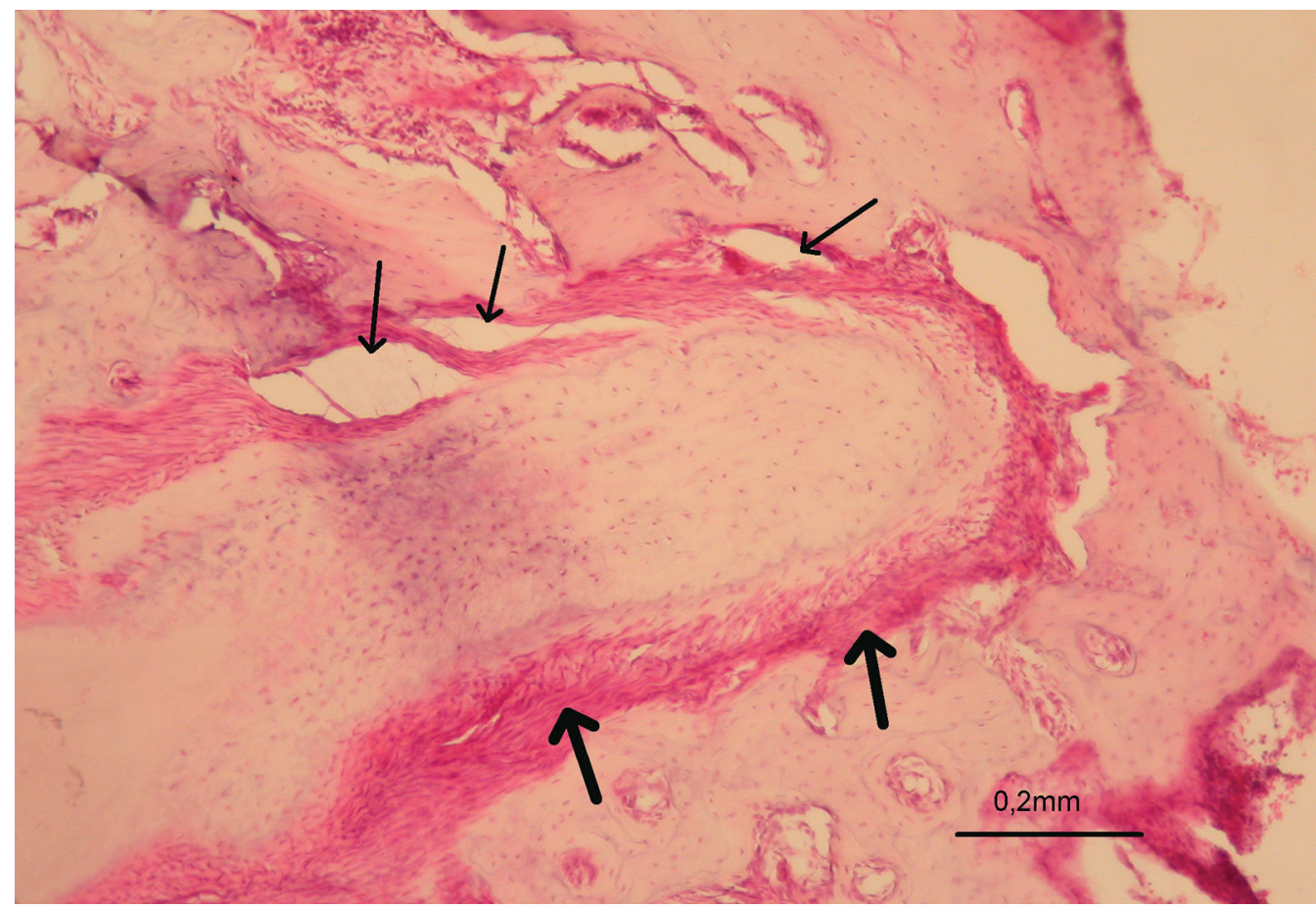

Fig. 5 A histologic section of a molar root from the fluoridated experimental group. Thin arrows indicate the stretching of the periodontal fibers at the tension side. Thick arrows indicate compression of the periodontal fibers at the compression side.

tension side, widening of the PDL space and stretching of the periodontal fibers were observed (-Figs. $\mathbf{5}$ and $\mathbf{6}$ ). At the tension side, decreased vascular supply to the PDL and destruction of cells between the stretched fibers occurred. At the compression side, resorption areas surrounded by multinucleated ostroclasts were observed at the alveolar bone surface adjacent to the PDL.
Histopathological evaluation revealed no significant difference between the sections obtained from the fluoridated and nonfluoridated groups. However, in the nonfluoridated group, significant resorption lacunae were observed in the roots of the 1 st molar teeth ( - Fig. 7) whereas no root resorption was observed in the fluoridated group ( - Fig. 5). 


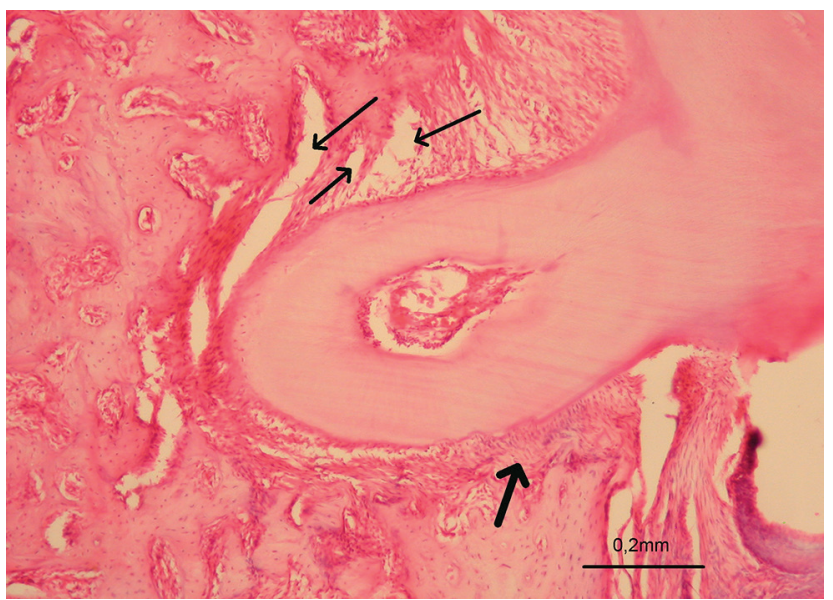

Fig. 6 A histologic section of a molar root from the nonfluoridated experimental group. Thin arrows indicate the stretching of the periodontal fibers at the tension side. Thick arrows indicate compression of the periodontal fibers at the compression side.

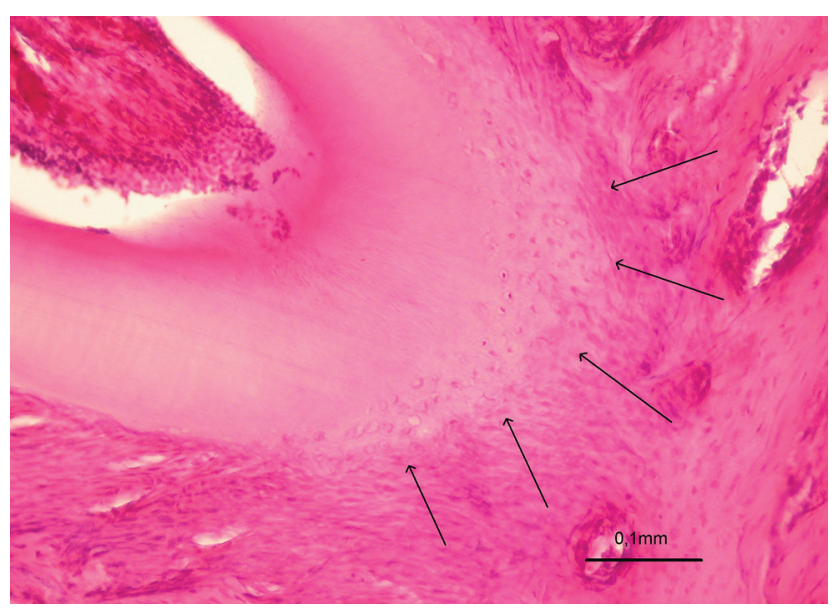

Fig. 7 A histologic section of a molar root from the nonfluoridated experimental group. Thin arrows indicate root resorption lacunae.

\section{Discussion}

Extended treatment times often accompany many complications such as enamel demineralization, root resorption and periodontal problems. ${ }^{15,16}$ Therefore, it is of great importance to understand the factors influencing bone resorption and deposition rates during orthodontic treatment. In the recent years, significant experimental and clinical research has been performed to accelerate orthodontic tooth movement. ${ }^{17-19}$ However, few studies have been published about the effects of fluoride on tooth movement, and in most studies, fluoride was administered only during orthodontic tooth movement. ${ }^{1,10,11}$ Zipkin and McClure $^{20}$ reported that during the period of rapid growth, both the percentage and total fluorine of the molar teeth, femurs and mandibles increased at a relatively rapid rate. In mature rats, fluorine storage does not increase with age. Furthermore, Matias et $\mathrm{a}^{21}$ reported that the formation of dentine, cementum, PDL, and alveolar bone in rats ended at week 8 . Thus, this study aimed at evaluating the effect of fluoride administration from gestation to birth and adulthood.
It has been reported that rat molars physiologically migrate in the distal direction with aging ${ }^{22,23}$ and occlusal forces play an important role in this migration. ${ }^{24} \mathrm{~A}$ splitmouth design was used for dental model measurements because of the physiological distal drift of the molars, physiological growth of the snout, forward movement of the incisors, and the possible distal tipping of the incisors used as anchorage. ${ }^{25}$ Compensation for these effects was performed by measuring the incisor-molar distances on the experimental and control sides. ${ }^{25,26}$ In this study, no statistically significant difference was observed in the amount of tooth movement between the fluoridated $(0.65 \mathrm{~mm})$ and nonfluoridated $(0.76 \mathrm{~mm})$ groups. In contrast with our results, Singer et $\mathrm{al}^{10}$ and Hellsing and Hammarstrom ${ }^{1}$ reported decreased tooth movement in the fluoridated groups and explained this result with the decreased osteoblastic activity. According to Gedalia and Zipkin, ${ }^{27}$ the incorporated fluoride gives rise to a mixed fluorohydroxyapatite and is therefore more resistant to resorption. Gonzales et al ${ }^{12}$ also agreed with this concept when discussing their findings of decreased tooth movement in the fluoridated group. In contrast, Karadeniz et $\mathrm{al}^{13}$ reported greater rates of tooth movement with heavy forces and high-fluoride intake in humans. However, their results could not be compared with the previous studies because force magnitude was an additional factor and because the study was conducted among humans.

Successful orthodontic tooth movement was observed on the experimental side of the rats with generated forces, which is consistent with previous studies. ${ }^{25,26}$ Although there was no orthodontic force on the control side, a slight decrease in incisor-molar distance was determined $(0.12 \mathrm{~mm})$. This might be due to the acting forces from the neighboring incisor teeth under heavy retraction forces.

Histomorphometric evaluation revealed that fluoride significantly reduced the number of osteoclasts in the experimental groups. This result was consistent with previous studies, which reported the inhibition of the osteoclastic activity with fluoride., ${ }^{8,28}$ Hellsing and Hammarstrom ${ }^{1}$ found that fluoride diminished orthodontic tooth movement as a result of reduced osteoclast density. Singer et $\mathrm{al}^{10} \mathrm{demon}-$ strated that fluoride intake might reduce the experimental tooth movement by interfering with osteoclastic activity and alveolar bone resorption. Okuda et $\mathrm{al}^{8}$ reported that the decrease in the number of osteoclasts was due to the toxic effects of fluoride concentrations on the osteoclasts.

Studies have demonstrated that the administration of fluoride stimulates the proliferation and differentiation of osteoblasts and consequently increases bone formation. ${ }^{6,30-33}$ Marie and Hott $^{31}$ reported that four weeks of fluoride supplementation induced a rapid $21.1 \%$ increase in the osteoblastic surface and a $26.3 \%$ stimulation of the bone matrix apposition rate, which resulted in a $29 \%$ increase in the amount of osteoid and in a $12 \%$ increase in the trabecular calcified bone density. Qu et al ${ }^{34}$ reported that NaF modulated osteoblast proliferation and differentiation in a dose-dependent manner and modified osteoblast metabolism. Yan et $\mathrm{al}^{35}$ also discovered this dose-dependent relationship. In our study, no statistically significant differences in the number 
of osteoblasts were detected between the two experimental groups. This finding might be due to high dose of (150 ppm) of NaF and its toxic effect on osteoblastic activity. In accordance with our results, Lundy et a ${ }^{36}$ and Kopp and Robey ${ }^{37}$ reported that $\mathrm{NaF}$ did not increase the number of osteoblasts.

In experimental groups, PDL space was narrowed on the compression sides, and compression of the periodontal fibers was also observed. On the tension sides, widening of the PDL space, stretching of the periodontal fibers, decreased vascular supply in the PDL and destruction of cells between stretched fibers were observed. On the compression sides, resorption areas surrounded by multinucleated osteoclasts were observed at the alveolar bone surface adjacent to the PDL. These are the characteristic histologic findings of orthodontic tooth movement which were consistent with the findings of other studies. ${ }^{38-41}$ The PDL space width at the tension sides did not differ between fluoridated and nonfluoridated groups. However, at the compression sides, PDL spaces were wider in the fluoridated group. This might be due to the inhibition of osteoclastic activity and tooth movement by fluoride.

Histopathologic examination revealed significant resorption craters in the 1 st molar roots of the nonfluoridated experimental group. On the contrary, no resorption was observed in the molar roots of the fluoridated experimental group. This finding might be due to the inhibition of the osteoclastic activity in the fluoridated group or due to fluoride making the cementum more resistant to resorption. ${ }^{29,42}$ Consistent with our results, Okuda et $\mathrm{al}^{8}$ reported that fluoride significantly decreased the number of resorption lacunae made by individual osteoclasts and the resorbed area per osteoclast. Foo et $\mathrm{a}^{43}$ also reported a reduced size of resorption craters, but the effect was variable and not statistically significant. Gonzales et $\mathrm{al}^{12}$ reported that fluoride reduced the depth, volume, and roughness of the resorption craters in the experimental groups. However, the area was similar to that in the positive control group. On the contrary, some researchers have reported no effect of fluoride on resorption activity. ${ }^{31,33}$

\section{Conclusions}

No difference was observed in the amount of tooth movement between the fluoridated and nonfluoridated groups. Fluoride significantly reduced the number of osteoclasts in the experimental groups. Osteoblastic activity increased in the tension sides but did not differ between the fluoridated and nonfluoridated groups. The PDL space widths at the tension sides did not differ between the fluoridated and nonfluoridated groups. However, PDL space widths at the compression sides were wider in the fluoridated group. Resorption craters were present in the 1st molar roots of the nonfluoridated experimental group. On the contrary, no resorption was observed in the molar roots of the fluoridated experimental group.

\section{Funding}

This study was funded by the Suleyman Demirel University, Scientific Researches Coordination Unit (grant number 1945-D-09).

\section{Conflict of Interest}

None declared.

\section{Acknowledgments}

We wish to thank Dr. Ozgur Koskan, from the Department of Zootechnics, Faculty of Agriculture of Suleyman Demirel University, for his help with statistical analyses, and Dr. Mustafa Cihat Avunduk, Department of Pathology, Faculty of Medicine of Selcuk University for his valuable help with histomophometric and histopathologic evaluation.

\section{References}

1 Hellsing E, Hammarström L. The effects of pregnancy and fluoride on orthodontic tooth movements in rats. Eur J Orthod 1991;13(3):223-230

2 Tyrovola JB, Spyropoulos MN. Effects of drugs and systemic factors on orthodontic treatment. Quintessence Int 2001;32(5):365-371

3 Dequeker J, Declerck K. Fluor in the treatment of osteoporosis. An overview of thirty years clinical research. Schweiz Med Wochenschr 1993;123(47):2228-2234

4 Kleerekoper M. The role of fluoride in the prevention of osteoporosis. Endocrinol Metab Clin North Am 1998;27(2):441-452

5 Farley JR, Wergedal JE, Baylink DJ. Fluoride directly stimulates proliferation and alkaline phosphatase activity of bone-forming cells. Science 1983;222(4621):330-332

6 Bellows CG, Heersche JN, Aubin JE. The effects of fluoride on osteoblast progenitors in vitro. J Bone Miner Res 1990;5(Suppl 1):S101-S105

7 Inoue $M$, Nagatsuka $H$, Tsujigiwa $H$, et al. In vivo effect of fluoride-substituted apatite on rat bone. Dent Mater J 2005;24(3):398-402

8 Okuda A, Kanehisa J, Heersche JN. The effects of sodium fluoride on the resorptive activity of isolated osteoclasts. J Bone Miner Res 1990;5(Suppl 1):S115-S120

9 Singh A, Dass R, Hayreh SS, Jolly SS. Skeletal changes in endemic fluorosis. J Bone Joint Surg 1962;44B(4):806-815

10 Singer J, Furstman L, Bernick S. A histologic study of the effect of fluoride on tooth movement in the rat. Am J Orthod 1967;53(4):296-308

11 Kebsch M, Wilkinson M, Petocz P, Darendeliler MA. The effect of fluoride administration on rat serum osteocalcin expression during orthodontic movement. Am J Orthod Dentofacial Orthop 2007;131(4):515-524

12 Gonzales C, Hotokezaka H, Karadeniz EI, et al. Effects of fluoride intake on orthodontic tooth movement and orthodontically induced root resorption. Am J Orthod Dentofacial Orthop 2011;139(2):196-205

13 Karadeniz EI, Gonzales C, Elekdag-Turk S, et al. The effect of fluoride on orthodontic tooth movement in humans. A two- and three-dimensional evaluation. Aust Orthod J 2011;27(2):94-101

14 Houston WJ. A new design of rat mouth prop. J Dent Res 1964;43:458

15 McComb JL. Orthodontic treatment and isolated gingival recession: a review. Br J Orthod 1994;21(2):151-159

16 Abuabara A. Biomechanical aspects of external root resorption in orthodontic therapy. Med Oral Patol Oral Cir Bucal 2007;12(8):E610-E613

17 Narmada IB, Rubianto M, Putra ST. The role of low-intensity biostimulation laser therapy in transforming growth factor. $\beta 1$, bone alkaline phosphatase and osteocalcin expression during orthodontic tooth movement in Cavia porcellus. Eur J Dent 2019;13(1):102-107 
18 Tehranchi A, Behnia H, Pourdanesh F, Behnia P, Pinto N, Younessian F. The effect of autologous leukocyte platelet rich fibrin on the rate of orthodontic tooth movement: A prospective randomized clinical trial. Eur J Dent 2018;12(3):350-357

19 Zou M, Li C, Zheng Z. Remote corticotomy accelerates orthodontic tooth movement in a rat model. BioMed Res Int 2019;2019:4934128

20 Zipkin I, McCLURE FJ. Deposition of fluorine in the bones and teeth of the growing rat. J Nutr 1952;47(4):611-620

21 Matias MA, Li H, Young WG, Bartold PM. Immunohistochemical localization of fibromodulin in the periodontium during cementogenesis and root formation in the rat molar. J Periodontal Res 2003;38(5):502-507

22 Cleall JF, Wilson GW, Garnett DS. Normal craniofacial skeletal growth of the rat. Am J Phys Anthropol 1968;29(2):225-242

23 Roberts WE, Morey ER. Proliferation and differentiation sequence of osteoblast histogenesis under physiological conditions in rat periodontal ligament. Am J Anat 1985;174(2):105-118

24 Tsuchiya S, Tsuchiya M, Nishioka T, Suzuki O, Sasano Y, Igarashi K. Physiological distal drift in rat molars contributes to acellular cementum formation. Anat Rec (Hoboken) 2013;296(8):1255-1263

25 Ren Y, Maltha JC, Van 't Hof MA, Kuijpers-Jagtman AM. Age effect on orthodontic tooth movement in rats. J Dent Res 2003;82(1):38-42

26 Ren Y, Maltha JC, Kuijpers-Jagtman AM. The rat as a model for orthodontic tooth movement-a critical review and a proposed solution. Eur J Orthod 2004;26(5):483-490

27 Gedalia I, Zipkin I, The Role of Fluoride in Bone Structure. St. Louis: W. H. Green; 1973

28 Lindskog S, Flores ME, Lilja E, Hammarström L. Effect of a high dose of fluoride on resorbing osteoclasts in vivo. Scand J Dent Res 1989;97(6):483-487

29 Taylor ML, Boyde A, Jones SJ. The effect of fluoride on the patterns of adherence of osteoclasts cultured on and resorbing dentine: a 3-D assessment of vinculin-labelled cells using confocal optical microscopy. Anat Embryol (Berl) 1989;180(5):427-435

30 Ream LJ. The effects of short-term fluoride ingestion on bone formation and resorption in the rat femur. Cell Tissue Res $1981 ; 221(2): 421-430$
31 Marie PJ, Hott M. Short-term effects of fluoride and strontium on bone formation and resorption in the mouse. Metabolism 1986;35(6):547-551

32 Chavassieux P. Bone effects of fluoride in animal models in vivo. A review and a recent study. J Bone Miner Res 1990;5(Suppl 1):S95-S99

33 Modrowski D, Miravet L, Feuga M, Bannié F, Marie PJ. Effect of fluoride on bone and bone cells in ovariectomized rats. J Bone Miner Res 1992;7(8):961-969

34 Qu WJ, Zhong DB, Wu PF, Wang JF, Han B. Sodium fluoride modulates caprine osteoblast proliferation and differentiation. J Bone Miner Metab 2008;26(4):328-334

35 Yan X, Feng C, Chen Q, et al. Effects of sodium fluoride treatment in vitro on cell proliferation, apoptosis and caspase-3 and caspase- 9 mRNA expression by neonatal rat osteoblasts. Arch Toxicol 2009;83(5):451-458

36 Lundy MW, Farley JR, Baylink DJ. Characterization of a rapidly responding animal model for fluoride-stimulated bone formation. Bone 1986;7(4):289-293

37 Kopp JB, Robey PG. Sodium fluoride lacks mitogenic activity for fetal human bone cells in vitro. J Bone Miner Res 1990;5(Suppl 1):S137-S141

38 Macapanpan LC, Weinmann JP, Brodie AG. Early tissue changes following tooth movement in rats. Angle Orthod 1954;24(2):79-95

39 Zaki AE, Vanhuysen G. Histology of the periodontium following tooth movement. J Dent Res 1963;42:1373-1379

40 Ong CK, Walsh LJ, Harbrow D, Taverne AA, Symons AL. Orthodontic tooth movement in the prednisolone-treated rat. Angle Orthod 2000;70(2):118-125

41 Jäger A, Zhang D, Kawarizadeh A, et al. Soluble cytokine receptor treatment in experimental orthodontic tooth movement in the rat. Eur J Orthod 2005;27(1):1-11

42 Taylor ML, Maconnachie E, Frank K, Boyde A, Jones SJ. The effect of fluoride on the resorption of dentine by osteoclasts in vitro. J Bone Miner Res 1990;5(Suppl 1):S121-S130

43 Foo M, Jones A, Darendeliler MA. Physical properties of root cementum: Part 9. Effect of systemic fluoride intake on root resorption in rats. Am J Orthod Dentofacial Orthop 2007; 131(1):34-43 